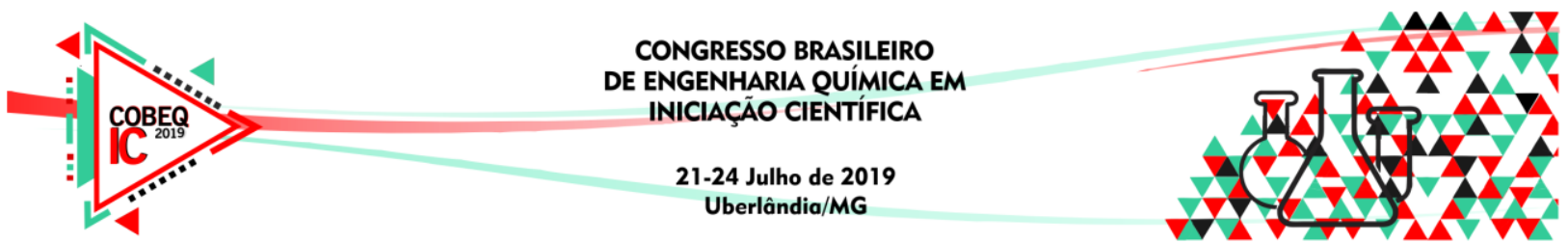

\title{
CARACTERIZAÇÃO DE SILICATOS DE TERRAS RARAS DO COMPLEXO JEQUIÉ-BA
}

\author{
F. A. SANTOS $^{1}$, R. E. COELHO ${ }^{1}$, P. C. D. FERNANDES ${ }^{2}$ e V. M. SANTOS ${ }^{1}$ \\ ${ }^{1}$ Instituto Federal de Educação, Ciência e Tecnologia da Bahia, Campus Salvador \\ ${ }^{2}$ Universidade do Estado da Bahia, Campus IV, Jacobina \\ E-mail para contato: francielealmeida20@gmail.com
}

\begin{abstract}
RESUMO - Amostras de silicatos de terras raras de rochas do Complexo Jequié BA foram analisadas para identificar minerais do grupo da chevkinita (silicato de $\mathrm{Fe}, \mathrm{Ti}$, terras raras leves, $\mathrm{Ca}, \mathrm{Th}, \mathrm{Al}$ ). As amostras são provenientes de trabalhos de mapeamento geológico em Jequié, onde foram identificadas rochas contendo altos teores de terras raras e tório cujas características sugeriam tratar-se de allanita. Posteriormente, o estudo da composição química destes minerais mostrou-se incompatível com a allanita e compatível com um mineral do grupo da chevkinita, a karnasurtita. Mas, a hipótese de ocorrência de karnasurtita é descartável, já que suas características físicas macroscópicas são diferentes do mineral analisado. Diante disso, a pesquisa prosseguiu nos laboratórios de Materiais do IFBA e de Petrologia Aplicada à Metalogênese da UFBA nos quais foi realizada a caracterização através do Microscópio Eletrônico de Varredura (MEV), Espectrometria de Raios X (EDS) e Difratometria de Raios X (DRX). Para tal, as amostras passaram pela moagem, peneiramento, limpeza, secagem e separação por métodos manuais e através da centrifugação. A análise no MEV e EDS forneceu dados da composição química que foram comparados com a média das composições de chevkinitas e perrieritas reportadas na literatura. Os resultados da caracterização no DRX sugeriram uma mudança de fase provocada pelo aquecimento ou a presença de um mineral ainda desconhecido.
\end{abstract}

\section{INTRODUÇÃO}

Em trabalhos de mapeamento geológico na região de Jequié, foram identificadas rochas contendo altos teores de terras raras e tório (Fernandes et. al, 2017) cujas características físicas em amostra de mão e ao microscópio petrográfico sugeriam tratar-se de allanita. Fernandes et. al (2017) determinaram a composição química destes minerais por MEV-EDS, verificando tratar-se de um aluminosilicato de terras raras leves (principalmente lantânio, cério e neodímio) e ferro com altos teores de tório, titânio e baixos teores de cálcio. Esta composição não seria compatível com allanita e sim com um mineral do grupo da chevkinita. O único possível mineral com composição que se aproxima das amostras estudadas seria a karnasurtita.

Entretanto, esta hipótese de ocorrência de karnasurtita é descartável, pois se trata de um mineral com características físicas diferentes do mineral analisado. A karnasurtita é cinza, tem brilho fraco e uma clivagem bem desenvolvida, já o mineral em estudo é preto, tem brilho 


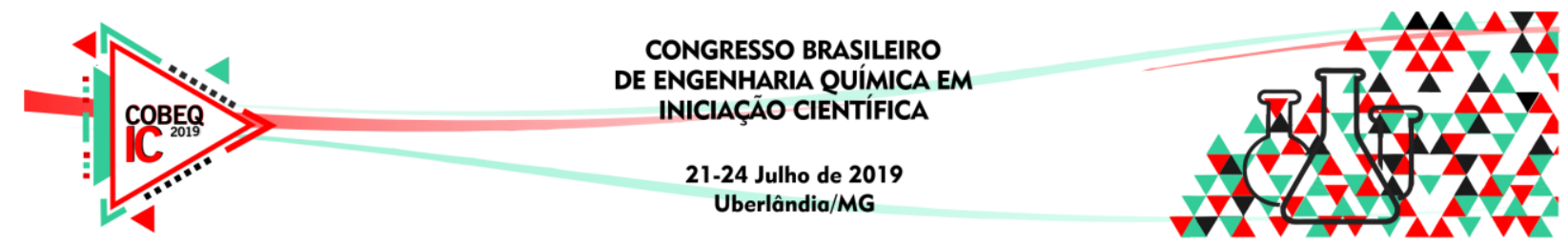

vítreo como o da obsidiana e possui uma fratura curva. A hipótese inicial do trabalho foi, assim, de que o mineral em questão fosse chevkinita ou perrierita. Estes minerais do grupo chevikinita são dimorfos, sendo a distinção entre eles difícil, pois ambos têm composições químicas e propriedades óticas semelhantes. Por meio do DRX, é possível diferenciar os dois minerais pelo ângulo $2 \theta$, sendo $100^{\circ}$ nas chevkinitas e $113^{\circ}$ nas perrieritas (Muhling et al., 2014). Um método para a recristalização das perrieritas e chevkinitas é o aquecimento a $1000^{\circ} \mathrm{C}$, ao ar e em atmosfera redutora. A chevkinita metamicta adquire a estrutura da chevkinita após aquecimento em nitrogênio por uma hora. Quando aquecida em ar, forma perrierita-(Ce) e $\mathrm{CeO}_{2}$. A chevkinita cristalina retém sua estrutura quando aquecida a $1300^{\circ} \mathrm{C}$. Já a perrierita metamicta sofre recozimento mantendo a estrutura da perrierita mesmo em altas temperaturas, conforme estudo de Lima-de-Faria (1962), cujas técnicas ainda são utilizadas como referêcias para preparação de amostra para DRX com a finalidade de identificar os minerais em estudo.

Nesta pesquisa, amostras de rochas do Complexo Jequié - BA foram analisadas com a finalidade de identificar minerais do grupo chevkinita, no qual a chevkinita e a perrierita são os membros mais comuns e em suas composições estão presentes elementos de terras raras (REE - Rare Earth Elements).

\section{METODOLOGIA}

As amostras de rochas passaram pela moagem para obtenção de granulometrias específicas. Depois, as amostras foram peneiradas obtendo-se as seguintes granulometrias em mesh: 150 a 170, 170 a 200 e menor que 200. Para melhor visualização dos grãos foi feita uma limpeza com água para remover as partículas mais finas resultantes da moagem de parte da amostra com granulação muito fina (200 mesh ou menor). Após a limpeza, as amostras foram secadas num forno mufla por duas horas numa temperatura de $100^{\circ} \mathrm{C}$.

Para a separação, inicialmente, utilizou-se pinça e lupa. Depois, foi feita por bateia cujo nome se refere a um utensílio usado na mineração em pequena escala. Mas, tendo em vista a necessidade de ter uma separação mais eficiente que a bateia, foi utilizada a técnica de centrifugação numa centrífuga de bancada.

$\mathrm{Na}$ centrifugação foram usados oito tubos de ensaio com capacidade para $15 \mathrm{ml}$. Em cada tubo de ensaio foi colocado aproximadamente 2,35 $\mathrm{g}$ da amostra com água deionizada. Os parâmetros usados foram: rotação de $1500 \mathrm{rpm}$ e tempo de 5 minutos. Concluída a centrifugação, os tubos de ensaio foram retirados da centrífuga observando-se a separação dos minerais, isto é, os minerais mais densos e escuros ficaram na parte inferior do tubo de ensaio e os minerais menos densos e claros ficaram na parte superior. A parte menos densa foi removida com uma pequena espátula. As etapas da centrifugação descritas até aqui foram repetidas mais duas vezes com a finalidade de separar melhor os minerais. Por fim, as amostras foram secadas no forno mufla a uma temperatura de $100^{\circ} \mathrm{C}$ por uma hora.

Após a separação, parte do material foi aquecido por uma hora a uma temperatura de $1000^{\circ} \mathrm{C}$ em atmosfera sem proteção e outra parte em atmosfera de nitrogênio. Tais tratamentos foram realizados baseando-se nos procedimentos utilizados por Lima-de-Faria (1962) que realizou um estudo clássico com a maior série completa de experimentos de 


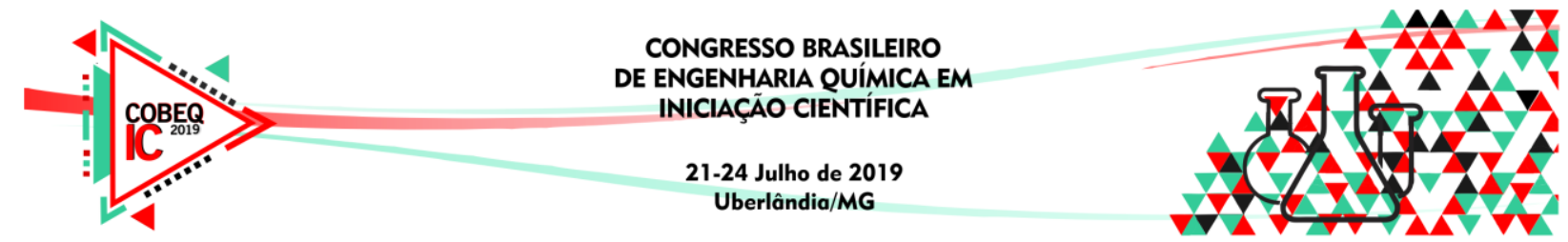

aquecimento, no ar e em nitrogênio em amostras de chevkinita e perrierita. Para o aquecimento das amostras foi utilizado um forno tubular equipado com retorta de alumina. $\mathrm{Na}$ caracterização da amostra, foi possível identificar os elementos presentes nos minérios, cujos resultados ajudaram na análise seguinte que foi o DRX. As fases presentes foram analisadas com base na composição química dos principais minerais constituintes da amostra. Em uma primeira tentativa foi analisada a amostra centrifugada sem tratamento térmico. Depois, as análises foram feitas com as amostras tratadas termicamente.

\section{RESULTADOS}

\subsection{Moagem e separação dos minerais}

A moagem no moinho planetário e o peneiramento proporcionaram a obtenção do material em granulometrias específicas que facilitaram os processos de separação e contribuíram para o controle do tamanho das amostras a serem analisadas nos equipamentos de caracterização. A separação com pinça e lupa se mostrou inviável por ser bastante demorada, já que os grãos eram muito pequenos. Sendo assim, optou-se por outro processo de separação: a centrifugação. Com esta técnica, separou-se um concentrado contendo cerca de $60 \%$ de minerais de terras raras (perrierita, chevknita) e cerca de $40 \%$ de hornblenda, de um concentrado, mais claro, contendo plagioclásio, apatita e traços de hornblenda. Após a centrifugação, a amostra mais densa ficou com um teor menor de minerais mais claros, sendo composta por cerca de $60 \%$ de minerais do grupo da chevkinita e $40 \%$ de hornblenda. Já a amostra menos densa, ao ser inspecionada sob a lupa, continha basicamente plagioclásio, apatita e traços de hornblenda. Na análise por MEV e EDS da amostra centrifugada, os resultados, embora não tenham sido quantificados, mostraram que houve aumento no número de grãos de minerais ferromagnesianos no material centrifugado, cujos elementos correspondem à composição química dos minerais do grupo chevkinita e hornblenda.

\subsection{Tratamento de dados e análise no MEV/EDS}

Após a separação dos minerais, foi realizada a análise da composição química no MEV/EDS. Chevkinita (Ce) e perrierita (Ce) são silicatos de Ti-Fe-REE com a fórmula genérica $\mathrm{A}_{4} \mathrm{BC}_{2} \mathrm{D}_{2} \mathrm{Si}_{4} \mathrm{O}_{22}$, onde: $\mathrm{A}=\mathrm{REE}, \mathrm{Y}, \mathrm{Ca}, \mathrm{Sr}, \mathrm{Th} ; \mathrm{B}=\mathrm{Fe}^{2+}(\mathrm{Mn}, \mathrm{Mg}) ; \mathrm{C}=\mathrm{Ti}, \mathrm{Al}, \mathrm{Fe}^{3}$ ${ }^{+}, \mathrm{Fe}^{2+}, \mathrm{Cr}, \mathrm{Mn}, \mathrm{Mg}, \mathrm{Zr}, \mathrm{Hf}, \mathrm{Nb} ; \mathrm{D}=\mathrm{Ti}$ (Macdonald e Belkin, 2009). Tendo em vista estes dados, utilizou-se o EDS para identificar a presença desses minerais com base na composição química. Os diagramas apresentados a seguir (Figura 1) são resultados da comparação entre a composição química das amostras de minerais pesados e centrifugados e a média das composições de chevkinitas e perrieritas reportadas na literatura (Macdonald e Belkin, 2009). $\mathrm{Na}$ ordenada plotou-se o quociente entre cada elemento obtido por MEV/EDS nas amostras e a média de chevkinitas (Figura 1: A e B) e perrieritas (Figura 1: C e D) disponíveis na literatura (Macdonald e Belkin, 2009). Em (A), razões obtidas pela divisão dos teores obtidos em amostras de lâminas delgadas polidas e a composição média de chevkinitas da literatura (Macdonald e Belkin, 2009). Em (B), o quociente entre a composição de grãos catados, moídos e centrifugados e a composição média de chevkinitas da literatura (Macdonald e Belkin, 2009) . Em (C) o quociente entre os grãos analisados em lâminas delgadas polidas e de perrieritas da literatura (Macdonald e Belkin, 2009). Em (D), o quociente entre a 


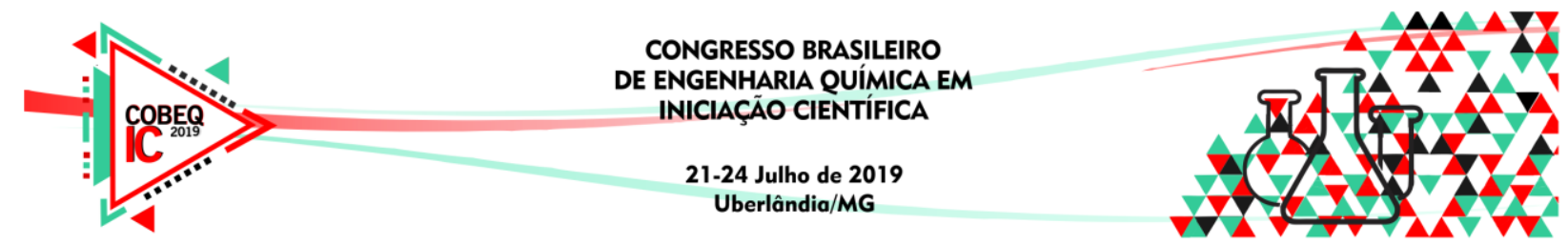

composição de grãos da amostra catada, moída e centrifugada e de perrieritas encontradas na literatura (Macdonald e Belkin, 2009).

Figura 1 - Comparação das amostras obtidas por MEV/EDS e a média de chevkinitas $(\mathrm{A}$ e $\mathrm{B})$ e perrieritas (C e D) disponíveis na literatura (Macdonald e Belkin, 2009).
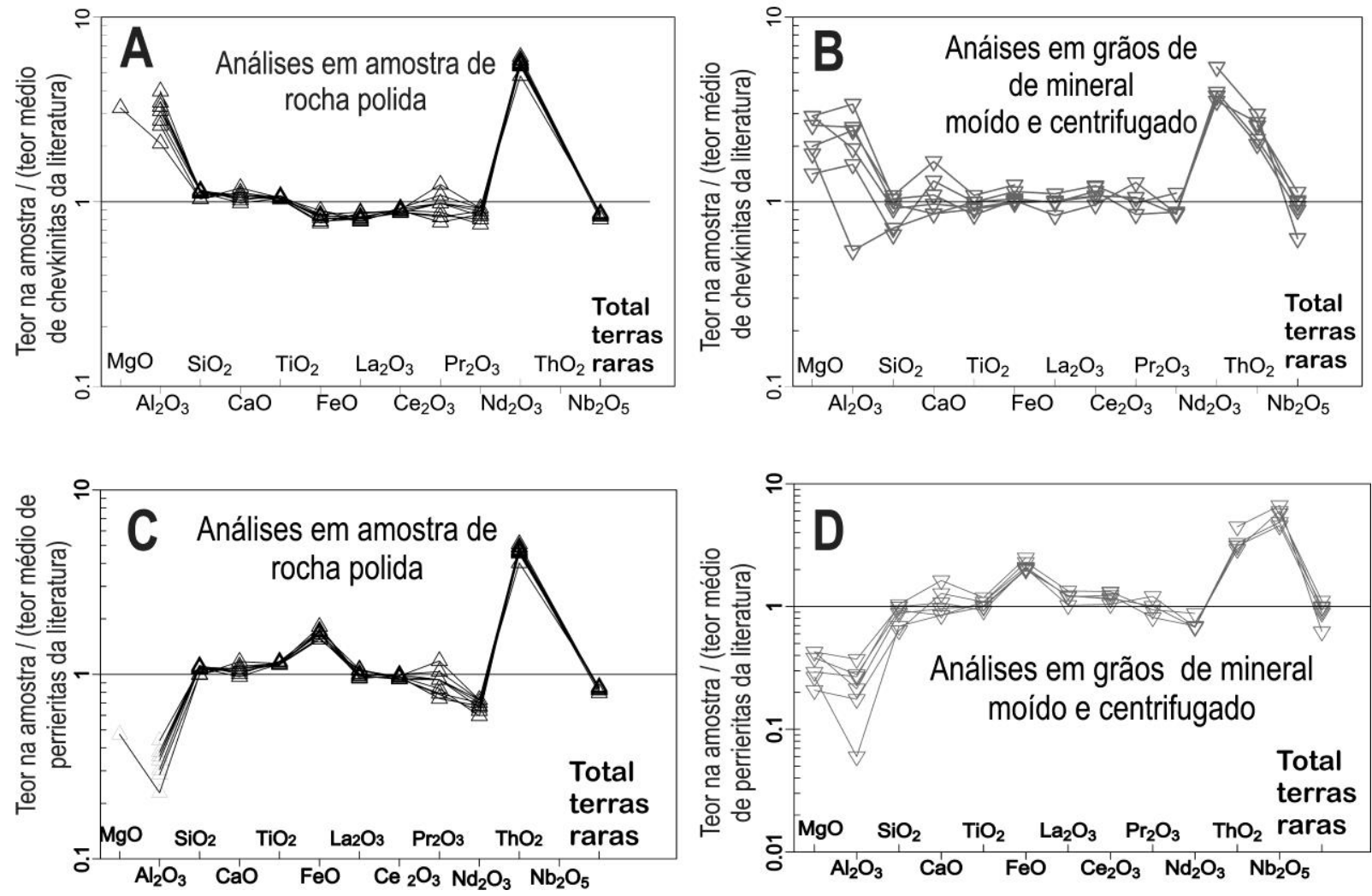

As análises de minerais pesados selecionadas por centrifugação (B) em comparação com aquelas análises em lâmina delgada polida (A) são mais ricas em magnésio e alumínio do que a média das chevkinitas (duas a três vezes mais), e muito mais ricas em tório (3 vezes mais) e nióbio (2 a 3 vezes). Os teores de silício, cálcio, terras raras e ferro são comparáveis aos das chevkinitas de outras partes do mundo. Ao serem comparadas com perrieritas reportadas na literatura ( $\mathrm{C}$ e $\mathrm{D})$ observa-se que as amostras do presente estudo são muito mais pobres em magnésio e alumínio e muito mais ricas em tório e nióbio do que as perrieritas reportadas na literatura (Macdonald e Belkin, 2009). Pode-se ainda observar que nas amostras moídas, bateadas e centrifugadas (B e D) as composições químicas têm uma maior variabilidade, o que pode ser devido ao fato de que a análise de amostras em grãos com superfície irregular tende a criar refrações secundárias e dispersão do feixe eletrônico. Além disso, pode ser observado que poucas das análises de amostras de rocha em forma de lâmina delgada e polida (A e C) apresentam teores detectados de magnésio. Esta diferença pode ser devida à heterogeneidade da amostra original pois, neste caso, as amostras de grãos (B e D) são mais representativas por terem sido formadas a partir de um maior volume de rocha, ou 


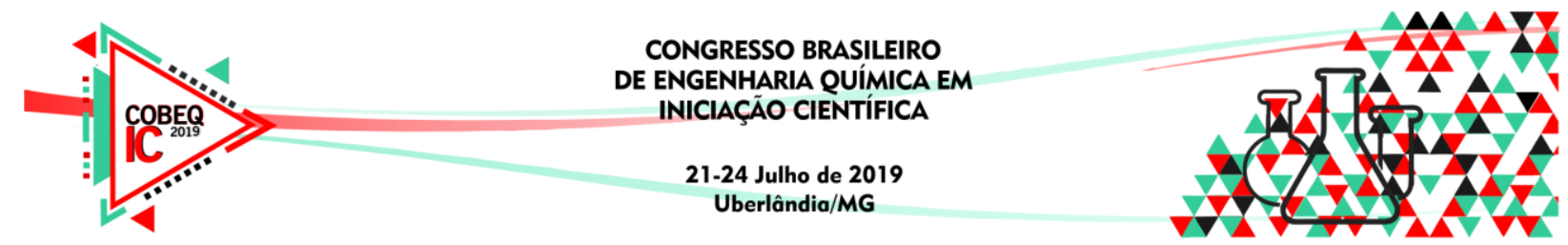

seja, a amostra inicial tinha cerca de $5 \mathrm{~kg}$ (cinco quilos) e a lâmina delgada e polida é, necessariamente, menos representativa do que os grãos provenientes da moagem da rocha.

\subsection{Tratamento de dados e análise por DRX}

A Figura 2 é um corte parcial ampliado dos difratogramas sobrepostos com foco nos picos de maior intensidade de ocorrência das amostras. Nela estão apresentados os difratogramas obtidos por DRX. O difratograma indicado pela letra a corresponde aos picos de difração da amostra sem tratamento, como obtida da centrifugação. O difratograma indicado pela letra $\mathrm{b}$ corresponde aos picos de difração da amostra tratada por uma hora, a uma temperatura de $1000^{\circ} \mathrm{C}$, sem proteção atmosférica. $\mathrm{O}$ difratograma indicado pela letra c corresponde aos picos de difração da amostra tratada por uma hora, a uma temperatura de $1000^{\circ} \mathrm{C}$ com proteção de $\mathrm{N}_{2}$. A Figura 2 possui ainda a identificação do $2 \theta$. Observa-se nesse corte parcial que nas amostras (a) e (c), os picos de difração apresentam $2 \theta$ praticamente na mesma posição, enquanto que o pico da amostra (b) deslocou para a direita, com um pequeno aumento. Tudo indica que o aumento do $2 \theta$ do difratograma (b) está relacionado com o tratamento sem proteção atmosférica, influenciado pela presença do oxigênio.

Figura 2 - Corte ampliado dos difratogramas.

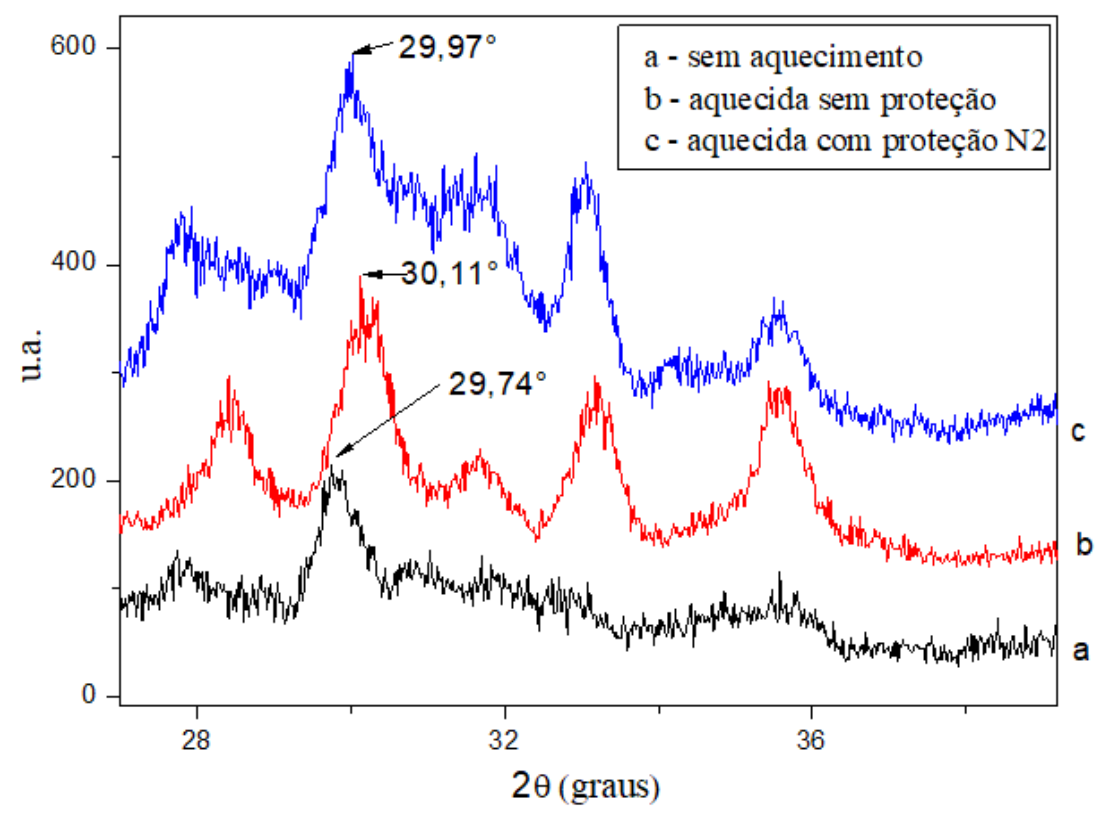

Uma explicação plausível para a diferença entre os picos de difração é que o material estudado pode possuir compostos ainda não indexados no padrão, sendo os ângulos $2 \theta$ resultantes nos difratogramas desconhecidos. Os ângulos $2 \theta$ de maior intensidade observados estão ligeiramente deslocados, outros de menor intensidade coincidem com os ângulos $2 \theta$ do padrão, mas não é condição suficiente para afirmar que sejam dos minerais chevkinita e perrierita. A morfologia, ou até mesmo uma pequena variação na composição pode ter influenciado nesse deslocamento. Além disso, deve-se consideradar a metamictização da amostra, ou seja, a destruição da rede cristalina devido à radioatividade do tório, um elemento que ocorre em concentração alta nos minerais do grupo da chevkinita (Klein, 2012). Assim, 


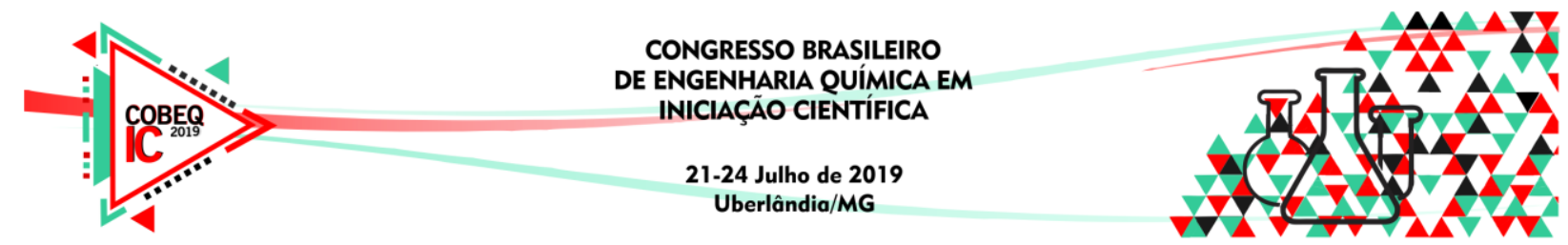

está sendo estudado um minério com diferenças encontradas naqueles indexados no padrão de difração, isso porque no EDS foram obtidos valores indicando composições próxima dos mesmos, porém o EDS é uma análise semi-quantitativa. Portanto, caberia outros estudos com técnicas diversas, como fluorescência de raios-X e microscopia eletrônica de transmissão. Tudo indica, pelo resultado observado nos difratogramas, que as condições apresentadas desse minério possuem variações diferentes dos materiais de outras regiões, pois não há nada semelhante nos padrões de difração do PDF-2 - 2003.

\section{CONCLUSÕES}

A etapa de separação foi uma das mais trabalhosas, pois a separação de minerais com tamanhos de aproximadamente $300 \mu \mathrm{m}$ requer técnicas bastante específicas. A escolha da técnica de separação por centrifugação possibilitou melhores resultados que as técnicas de separação com pinça e lupa ou por bateia. Apesar das análises realizadas no MEV/EDS confirmarem a presença de elementos químicos constituintes dos minerais do grupo chevkinita, observou-se que os teores de tório, nióbio, magnésio e alumínio das amostras de Jequié são muito mais altos do que aqueles encontrados em perrieritas ou chevkinitas reportadas na literatura, o que pode reforçar a hipótese de um mineral ainda desconhecido do grupo da chevkinita. O DRX mostrou que os minerais analisados não correspondem aos minerais pesquisados na base de dados do DRX. Os resultados indicam que o aquecimento em atmosferas de ar e nitrogênio feito para recristalizar a amostra, interferiram pouco na mudança da estrutura cristalina desses minerais, porém surgiram picos de menores intensidades, sugerindo a presença de um mineral do grupo chevkinita até o momento desconhecido. Para a identificação desta fase mineral será necessário recorrer a DRX in situ, obtendo-se difratogramas de grãos individuais, a análises quantitativas por microssonda eletrônica e a outras possíveis técnicas como fluorescência de raios-X.

\section{REFERÊNCIAS}

FERNANDES, P.C.D.; FRANTZ, J. C.; RIOS, D. C.; PORCHER C. C.; DAVIS, D. W.; CONCEIÇÃA, R. V.; COELHO, R. E. REE Mineralizations in perrierite hornblendite cumulates and mafics of the Archean Jequié Complex. UNEB, 2017.

KLEIN, C. Manual de Ciência dos Minerais. 23ª edição. Porto Alegre: Bookman, 2012.

LIMA-DE-FARIA, J. Heat treatment of cheviknite and perrierite. Mineralogical Magazine, Volume 33, 1962.

MACDONALD, R., BELKIN, H. E. Compositional variation in the chevkinite group: new data from igneous and metamorphic rocks. Mineralogical Magazine, Volume 66, 2009.

MUHLING. J.R.; SUVOROVA, A.; RASMUSSEN, B. 2014. The occurrence and composition of chevkinite- $(\mathrm{Ce})$ and perrierite- $(\mathrm{Ce})$ in tholeiitic intrusive rocks and lunar mare basalt. American Mineralogist, Volume 99, 2014. 